\title{
MODELING OF HEAT ENERGIES AND FORCES IN FRICTION STIR WELDING
}

\author{
Yaser Hadi \\ Department of Mechanical Engineering Technology, \\ Yanbu Industrial College, Saudi Arabia
}

\begin{abstract}
Since its inception, friction stir welding, FSW has been promising easy operation and environmental stewardship through contact friction between the tool and the weld part. The Aluminum alloy 2024-T351 was used in both working pieces. Six processes in FSW may include sticking, plunging into the welding pieces, half and full sliding, full welding along the joint line for the weld to be created, and spacing when picking away the welding tool from the weld. In determining the weld quality, their values should be within a safe range during the welding process, to derive heat from friction, modifying the parameters of the process causes variation in force in the traverse and axial directions. The ability to measure forces and understand their relationship with welding parameters is essential to a successful FSW energy strategy. The analytical models presented in this study depict each welding phase as it occurs and can be applied to predict welding forces and the heat energies.
\end{abstract}

Keywords: FSW, Heat Energy, Welding Force, End Mill, MatLab Model.

Cite this Article: Yaser Hadi. Modeling of Heat Energies and Forces in Friction Stir Welding. International Journal of Mechanical Engineering and Technology (IJMET), 12(9), 2021, pp. 1-12.

https://iaeme.com/Home/issue/IJMET?Volume $=12 \&$ Issue $=9$

\section{INTRODCUTION}

A Friction Stir Welding (FSW) joint is a solid-state plastic joining method used to join sheets and panels. FSW is primarily used to make aluminum butt joints, prevalent in the aluminum industry [1]. Methods used when the metal's properties do not change during the welding process and are recognized as one of the most innovative modern welding systems [2], particularly for alloys, which cannot be welded through conventional methods. A layer of metal is welded at a lower temperature than its melting point [3], which applies to alloys like 2024T351 used in aerospace structures, but their low tensile strength is a notable problem. In the heat-affected region (HAZ), due to the amount of heat entering the welding area during the welding process, cell growth increases, resulting in a decrease in hardness as well as cracks in the welds such as hardening cracks [4].

The rotation of the friction welding tool causes the material to be welded to mix and stir. This cylindrical-shaped tool is designed with a stitch bump at the bottom end, and the process 
continues until the bottom surfaces of the tool and the panel to be welded are in complete contact. The welding tool and its support protrusion, on the one hand, and the piece to be welded, on the other, cause the piece to be welded to reach high temperatures [5]. With rotating motion, a fine metal fills the gap between the two edges and holds the stitch bump in place. Linear and rotational speeds have the most significant impact on the welding temperature of alloy 2024-T351 [6]. The rate of rotated tool decreases welds joint strength and efficiency while traveling speed decreases as ductility increases. It has been done before [7] to model the FSW process using a thermomechanical model compared to a heat generator for the FSW tool. However, there are some drawbacks. Therefore, a model has been developed to characterize heat generation and study the welding force and the period. In this embodiment, heat generation represents frictional heat generated by the tool ends, with constant upper pressure and frictional slip assuming place at the tool's interface, allowing radially dependent surface heat flow distribution.

In frictional processes, heat is generated by the presence of continuous frictional stress at the interface. Apparently, no consideration was given to the estimated analytical probe heat generation. An analytical estimation of the heat generation in FSW is clearly presented in a material flow model that considers strings. The material flow around the probe and shoulder can be identified using a 2D solid mechanical model. Monitor and control of the FSW process require acceptable models, such as MatLab. It consists of a set of welding conditions that are used to predict welding force variations over time. Its initial development phase has focused on predicting FSW forces during simple flat end milling operations. As a result of its greater flexibility, simulation provides more information, mainly when general solutions are unavailable [8]. The resulting relationships between welding parameters are considered dynamic welding forces. Welding parameters control how well welding particles overlap, and thus whether or not welding particles produce the necessary energies. Due to this, the optimal output depends on both the given variable input and the equations describing the system's dynamic characteristics.

\section{ALUMINIMUM ALLOYS}

Aluminum is a ductile, soft, resilient, lightweight metal [9] with a strong thermal and electrical conductor. It can be classified into different groups depending on how it reacts to thermal and mechanical treatment. There are many applications for Aluminum alloys, from simple to complex, such as the construction of aircraft bodies. Generally speaking, the first four digits of the wrought aluminum identification system $(\mathrm{Xxx})$ indicate the primary alloying element, as in series 2000 [10]. 2024 is an example, where two stand for copper content, zero indicates nonmodified alloy, and 24 indicates the ID number. Among the advantages of the 2xxxx series is its excellent mechanical properties at high temperatures [11].

\section{HEAT GENERATION MODELS}

The heat generation model for the material 2024-T351 Aluminum alloy was designed and parameterized. Tables 4 and 5 illustrate how the model combined into a prediction of overall weld performance with properties known to be correlated. Figure 1 shows the welder tool's movement and immersion in the weld piece. The thermal cycle significantly affected the plastic deformation that occurred near the weld region [12]; this may be due to the plastic deformation and low temperatures encountered during welding. In addition, there are grains in the stirred zone because of severe plastic deformation, which has resulted in the formation of the dynamic recrystallized zone [13]. In friction stir processing, a stirred zone is used to describe a large volume of the processed material. 


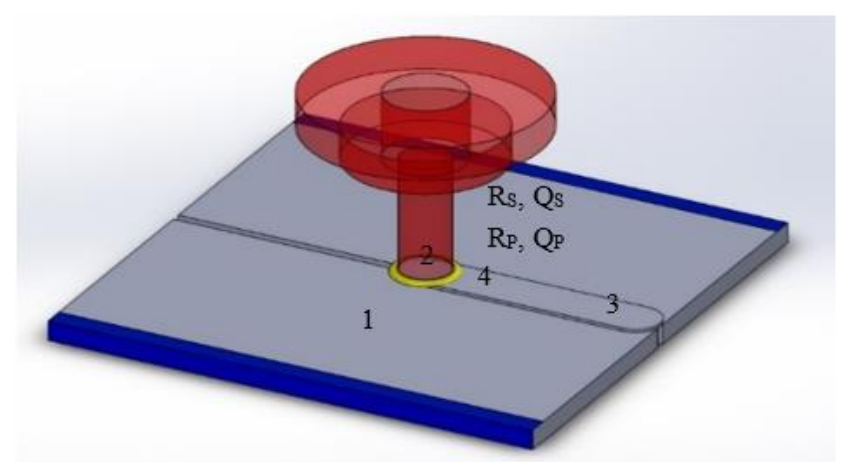

1. Workpiece (base metal), 2. Welding tool, 3. Deformed material generation sources, 4. Generative heat layer of material, $R_{S}, Q_{S}:$ Tool shoulder radius and shoulder heat generation, $R_{P}, Q_{P}$ : Tool probe radius and probe heat generation.

Figure 1 Schematic of heat generation during FSW

In this embodiment, several simulations are performed to examine how welding factors affect the forces and energies produced during welding stages. Figure 1 shows how welding heats workpiece material by reciprocating a shoulder parallel to the joint line. The energy values of a welding process were calculated in each stage using reward calculation techniques. An optimal method to estimate the energy emitted by the welding probe during contact with the workpiece and correlate it with the welding forces at each stage has been proposed [14]. Different stiffener shapes were simulated on panels. A FSW joint provides some perspective concerning the structure's overall stability based on the impact of the heat generation [15]. Heat generation $(\mathrm{Q})$ at the infinitesimal surface of the weld bits can be described by:

$$
\begin{gathered}
\mathrm{Q}=\omega \mathrm{r} \tau_{\mathrm{c}} \mathrm{A}=\pi \tau_{\mathrm{c}} \omega \mathrm{R}^{3} \\
\mathrm{Q}=\omega \mathrm{F}_{\mathrm{Z}} \mathrm{R}
\end{gathered}
$$

As the contact condition is the most critical aspect of the numerical model when modeling the FSW process [16], the top surface segment, in this case, is the tool segment and moves with velocity $\omega$. In the reciprocal bulk reaction scenario, the tool responds rigidly to normal displacement as opposed to the soft aluminum matrix, causing the contact pressure to change from zero to state-dependent pressure, resulting in a simpler, more complex, dynamic situation.

\subsection{Heat Generation Ratios}

Based on the geometry of the tool [17], the ratio of heat generation, i.e., contributions from different surfaces to total heat generation, is determined as follows:

$$
\mathrm{f}_{\mathrm{S}}=0.86, \mathrm{f}_{\mathrm{P}}=0.11, \mathrm{f}_{\mathrm{PT}}=0.03
$$

where the tool dimensions $\left(R_{S}\right.$ and $\left.R_{P}\right)$ are $R_{S}=10 \mathrm{~mm}, R_{P}=0.5 R_{S}=5 \mathrm{~mm}$. The shoulder generates the vast majority of the heat generated by the particular tool geometry. In contrast, the heat generated by the probe tip is relatively insignificant compared to the total generated heat.

\subsection{Probe and Shoulder Heat Generation}

As heat is generated at or near the contact surfaces during torsion swing [18], based on the tool shape, Fig. 1, it is assumed that an analytical tool has a horizontal shoulder surface, a vertical cylindrical side surface, and a flat head surface. In Figure 1, heat generated under the tool shoulder will be denoted by $\left(\mathrm{Q}_{\mathrm{P}}\right)$ while the heat generated by the tool probe will be denoted by 
$\left(Q_{S}\right)$. Rather than considering the probe as a cylindrical surface with radius $\left(R_{P}\right)$ and height $\left(\mathrm{H}_{\mathrm{P}}\right)$, the heat is generated only at the sides of the probe $\left(\mathrm{Q}_{\mathrm{P}}\right)$, the radiative energy at the tip surface is ignored according to the heat generation ratio $\left(f_{\mathrm{PT}}=0.16\right)$. Thus, the total value of $\left(\mathrm{Q}_{\mathrm{T}}\right)$ is derived from the heat of the shoulder and the probe surface. The total heat generation $\left(\mathrm{Q}_{\mathrm{T}}\right)$ of a rotating FSW tool and a stationary weld piece is estimated by flat circular shoulders and cylindrical probe surfaces [19], as given in equation 3:

$$
\mathrm{Q}_{\mathrm{T}}=\mathrm{Q}_{\mathrm{S}}+\mathrm{Q}_{\mathrm{P}}
$$

The shoulder area generates a shoulder's heat generation (QS). It can be calculated by using equation 4:

$$
\mathrm{Q}_{\mathrm{s}}=\pi \tau_{\mathrm{c}} \omega \mathrm{Rs}_{\mathrm{s}}^{3}
$$

Plunge, slide, and full welding are calculated by multiplying equation 4 by HS:

$$
\mathrm{Q}_{\mathrm{s}}=\pi \tau_{\mathrm{c}} \omega \mathrm{R}_{\mathrm{s}}{ }^{3} \mathrm{H}
$$

Essentially a cylinder with a radius and height of Rp and HP respectively, the heat produced by the probe, along with for sliding and full welding, is:

$$
\mathrm{Q}_{\mathrm{P}}=\pi \tau_{\mathrm{c}} \omega \mathrm{R}_{\mathrm{P}}^{3} \mathrm{H}_{\mathrm{P}}
$$

Calculation of total heat produced is performed using equations 4 and 5 by substituting them in equation 1 .

$$
\mathrm{Q}_{\mathrm{T}}=\pi \tau_{\mathrm{c}} \omega\left(\mathrm{R}_{\mathrm{S}}^{3} \mathrm{H}_{\mathrm{S}}+\mathrm{R}_{\mathrm{P}}{ }^{3} \mathrm{H}_{\mathrm{P}}\right)
$$

The mechanism is based on the general assumption of a constant contact shear stress $\tau \mathrm{c}$, but it varies depending on whether the sliding or sticking condition is present. As a function of the two associated quantities probe and shoulder location, the analytical result for heat generation is correlated with axial plunging and clockwise direction of the weld tool direction. The contact shear strength as a function of longitudinal stress fitted as $\tau c=\sigma y / \sqrt{ } 3$, where $\sigma y$ is Yield Tensile Strength (YTS), estimated from the following link which is $310 \mathrm{MPa}$, therefore $\tau \mathrm{c}=108 \mathrm{MPa}$, [20]. Based on equation 2, the estimated values for the heat produced by the shoulder and the probe are as follows:

$$
\begin{aligned}
& \mathrm{Q}_{\mathrm{S}}=\omega \mathrm{FR} \mathrm{R}_{\mathrm{S}} \mathrm{H}_{\mathrm{S}} \\
& \mathrm{Q}_{\mathrm{P}}=\omega \mathrm{FR} \mathrm{R}_{\mathrm{P}} \mathrm{H}_{\mathrm{P}} \\
& \mathrm{Q}_{\mathrm{T}}=\omega \mathrm{F}\left(\mathrm{R}_{\mathrm{S}} \mathrm{H}_{\mathrm{S}}+\mathrm{R}_{\mathrm{P}} \mathrm{H}_{\mathrm{P}}\right)
\end{aligned}
$$

\subsection{Probe, Shoulder, and Plate Parameters}

The heat generation and force MatLab models and the parameters of the FSW tool are listed in Table 1. For 2024-T351 aluminum alloy raw material, axial depth of cuts at spindles equals shoulder $\left(\mathrm{H}_{\mathrm{S}}\right)$ plus probe $\left(\mathrm{H}_{\mathrm{P}}\right)$. As regenerative force simulations are run in short steps, the forces on each surface involved in the weld are calculated at each step and affected by feed rate, spindle speed, and surface leftover from previous welds. Simulations were undertaken to determine the relationship between feed rate (f) and spindle speed $(\omega)$. The data used in the validated model are listed in Table 1, reflecting the values of $\omega, 750 \mathrm{rpm}$, and feed rate $\mathrm{f}, 120$ $\mathrm{mm} / \mathrm{min}$. Simulator programs have been written in Matlab using M-files. Among the inputs for the simulation program are feed rate $(f)$, spindle speed $(\omega)$, axial depth of the weld $\left(A_{D}\right)$, FSW tool diameter $\left(\mathrm{D}_{\mathrm{S}}\right)$, radial depth of the weld $\left(\mathrm{R}_{\mathrm{D}}\right)$, and 1000 number of samples $(\mathrm{NS})$. 
Table 1 An overview of welding tool parameters in the MATLAB model

\begin{tabular}{|c|c|c|c|c|c|}
\hline $\begin{array}{c}\text { Shoulder } \\
\text { diameter, } D_{\mathrm{S}} \\
(\mathrm{mm})\end{array}$ & $\begin{array}{c}\text { Probe } \\
\text { diameter, } \mathrm{D}_{\mathbf{P}} \\
(\mathrm{mm})\end{array}$ & $\begin{array}{l}\text { Mass, m } \\
\quad(\mathbf{k g})\end{array}$ & $\begin{array}{c}\text { Moment of } \\
\text { Inertia, I } \\
(\text { mm4) }\end{array}$ & $\begin{array}{l}\text { Length, } \\
1 \text { (mm) }\end{array}$ & $\begin{array}{c}\text { Modulus of } \\
\text { elasticity, E (GPA) }\end{array}$ \\
\hline 20 & 8 & $127.53 \mathrm{e}-3$ & 7853.982 & 122 & 73.1 \\
\hline $\begin{array}{l}\text { FSW rotational } \\
\text { Speed, rpm } \\
\text { (rad/sec.) }\end{array}$ & $\begin{array}{l}\text { Stiffness for } \\
\text { each mode, } \\
(\mathrm{N} / \mathrm{mm})\end{array}$ & $\begin{array}{l}\text { Radial Depth of } \\
\text { Cut, DR (mm) }\end{array}$ & $\begin{array}{l}\text { Axial Depth of } \\
\text { Cut, } A_{D}=\text { Mat. } \\
\text { Thickness, T, } \\
(\mathrm{mm})\end{array}$ & $\begin{array}{l}\text { Feed } \\
\text { Rate, } \mathrm{f} \\
(\mathrm{mm} / \mathrm{mi} \\
\mathrm{n})\end{array}$ & $\begin{array}{l}\text { Yield Tensile } \\
\text { Strength, YTS, } \\
\text { (MPa) }\end{array}$ \\
\hline $\begin{array}{c}750(78.5) \& 900 \\
(94.2)\end{array}$ & $\mathrm{KX}=\mathrm{kY}=7 \mathrm{e} 7$ & 20 & 7 & 0.16 & 310 \\
\hline \multicolumn{6}{|c|}{ Welding Force Coefficients, Al. } \\
\hline \multicolumn{3}{|l|}{$\mathrm{CT}=662$} & \multicolumn{3}{|c|}{$\mathrm{WT}=0.2068$} \\
\hline \multicolumn{4}{|l|}{$\mathrm{CR}=0.2039$} & \multicolumn{2}{|c|}{$\mathrm{WR}=0.297$} \\
\hline
\end{tabular}

Model inputs include feed rate (f), spindle speed $(\omega)$, axial depth of welding $\left(A_{D}\right)$, FSW tool diameter $\left(D_{S}\right)$, radial depth of welding $\left(R_{D}\right)$, and 1000 samples $\left(\mathrm{N}_{S}\right)$. The simulation program generates a simulation of the welding force components $\mathrm{F}_{\mathrm{X}}, \mathrm{F}_{Y}$, and $\mathrm{F}_{\mathrm{Z}}$. Based on an analytical model with a shoulder radius of $10 \mathrm{~mm}$, zero cone angle of $0^{\circ}$, and a probe height of $5 \mathrm{~mm}$, there was a root layer of $0.5 \mathrm{~mm}$ between the tip of the probe and the plate back. For the axial weld, the welder uses a probe with a radius of $0.5 \mathrm{R}_{\mathrm{S}}(5 \mathrm{~mm})$, a length of $\mathrm{H}_{\mathrm{P}}=\mathrm{R}_{\mathrm{P}}$, and a diameter of $0.2 R_{S}$. AD is rewarded with HT for the weld, which will avoid contact with the upper surface of the fixture. In both cases of probe and shoulder, the heat generation estimated analytically will replicate the total heat generation values $\left(\mathrm{Q}_{\mathrm{T}}\right)$ from Table 2; hence, a criterion for determining the contact condition is still necessary. A butt joint was prepared with two plates of the 2024-T351 alloy and fixed on a backing plate that was locally manufactured to study the effect of friction stir welding factors on jointing efficiency. The plates could be easily welded together without having to mind the surfaces' conditions.

Table 2 Shows the probe and shoulder heat generation at various stages, according to equations 5, 6, and 7 or equations 8,9 , and 10 .

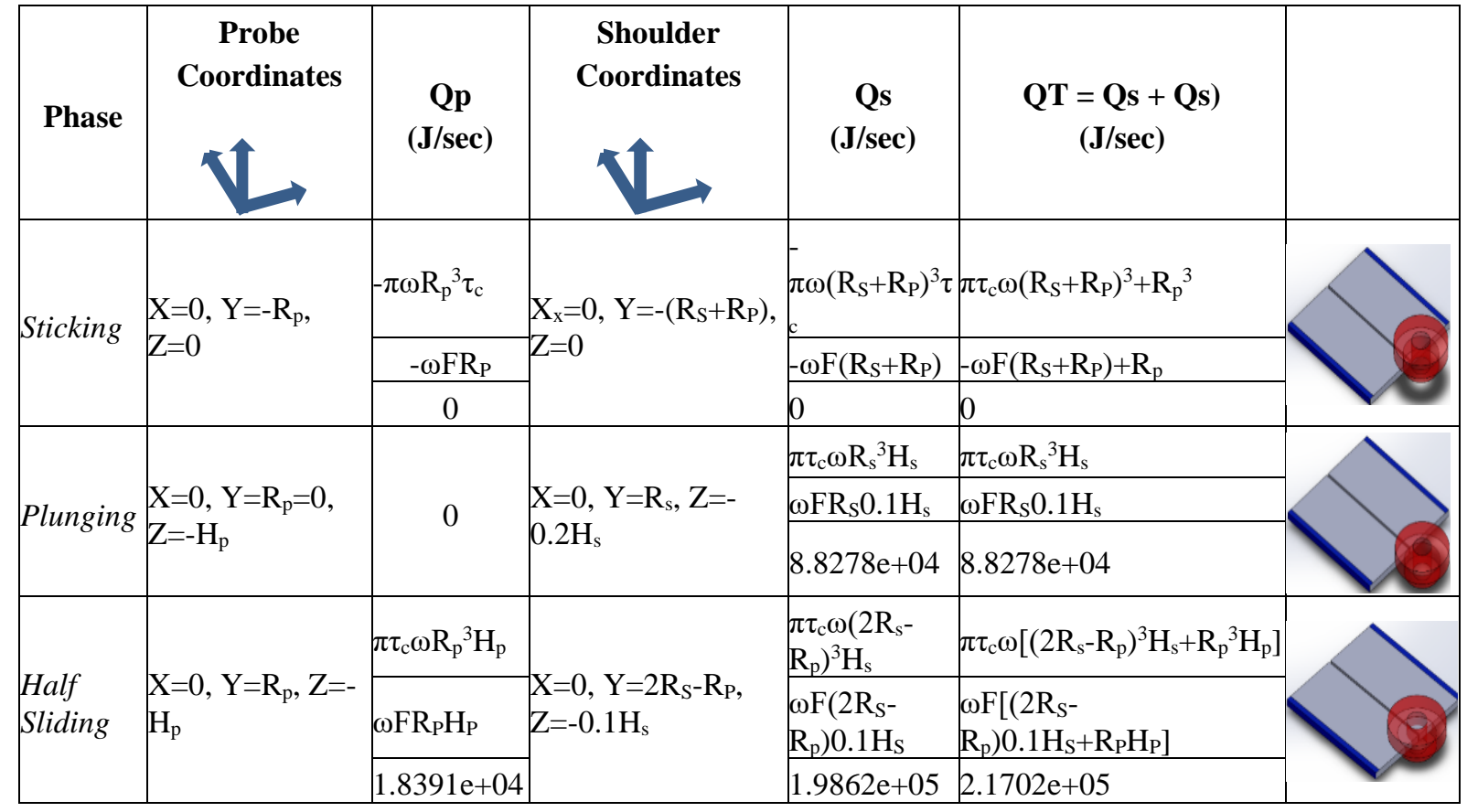




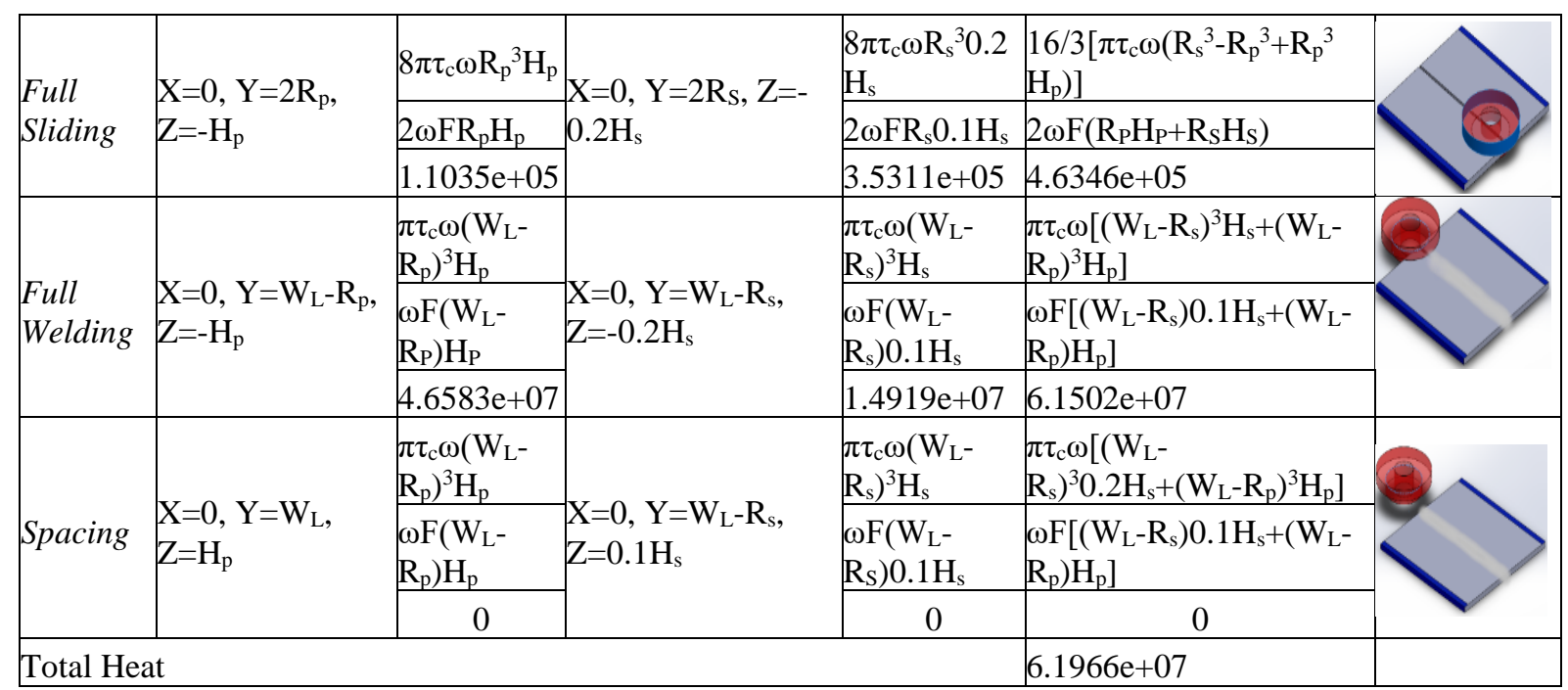

\section{VARIATION IN WELDING FORCES}

The welding forces can be recorded using models [21, 22, 23]. As a result, forces and time allow for observation, capturing, and analyzing. An understanding of the entire welding process can be gained from force-time diagrams of 2024-T351 alloys. Tables 2 and 3 show how the welding cycle works as the tool plunges into the workpiece, sinks, turns, softens, and welds in the desired direction in the welding process. The axial downward forces $\left(\mathrm{F}_{\mathrm{Z}}\right)$ remain constant during the welding stage but produce a minor effect compared to the $F_{X}$ and $F_{Y}$ forces. This occurs because a change in the rotational speed of the welding tool increases the temperature of the shoulder contact.

$$
\mathrm{F}_{\mathrm{Z}}=\pi \tau_{\mathrm{c}} \mathrm{R}^{2}
$$

An essential factor of FSW is axial force $\left(\mathrm{F}_{\mathrm{Z}}\right)$, which is affected by several factors, including welding rotational speed, tool shoulder, and probe diameter $[24,25]$. As a result of the indirect relationship, rotational speed has a smaller effect on $F_{X}$ and $F_{Y}$. The shoulder surface temperature and the probe circumference increase when the linear speed of the welding piece increases, as before. Table 1 shows the parameters used in the MatLab model and their effects on the situation under which the model ran.

\subsection{Simulation of the Welding Force}

For $\theta \mathrm{S} \leq \theta \leq \theta \mathrm{E}$, where $\theta \mathrm{S}$ is the angle at which the cutter enters the cut and $\theta \mathrm{E}$, is the angle at which the welder exits the weld. The angle at exit $\left(\theta_{\mathrm{E}}\right)$ is approximately zero. The angular spacing between flutes on the cutter $(\gamma)$, where $\gamma=360 / T=360$, assuming that the welding shoulder and its pen represent one tooth. A MatLab program is shown to calculate FSW forces for each welder's circumference throughout two revolutions. During the simulation, the angle of rotation will be kept constant for 1000 steps.

Several different plots illustrate the use of the program in relation to various numbers of welding engagements. The average welding forces represent the welding forces encountered in operation, and it is crucial to be aware of their levels while setting up the welding system. For example, the instantaneous welding angle can define a milling welder of uniform pitch $\theta \mathrm{I}$. Based on the plane system to relate the welding forces in end milling, down milling modes are determined as:

$$
\begin{aligned}
& F_{X A}=-F_{T A} \cos \left(\theta_{I}\right)-F_{R A} \sin \left(\theta_{I}\right) \\
& F_{Y A}=-F_{T A} \sin \left(\theta_{I}\right)+F_{R A} \cos \left(\theta_{I}\right)
\end{aligned}
$$




$$
\mathrm{F}_{\mathrm{ZA}}=\pi \tau_{\mathrm{c}} \tan \left(\theta_{\mathrm{I}}\right) \sec \left(\theta_{\mathrm{I}}\right)
$$

$\mathrm{F}_{\mathrm{XA}}, \mathrm{F}_{\mathrm{YA}}$, and $\mathrm{F}_{\mathrm{ZA}}$ are the average welding forces total acting on the welding tool per weld in $\mathrm{X}, \mathrm{Y}$, and $\mathrm{Z}$ directions, respectively. After the tool shaft rotation operation stage, the probe is moved to stick the primitive point in the dividing line. After that, twenty percent of the RS depth range is plunged with the tool until the tool shoulder attaches to the upper surface of the weld material. Due to axial force, rotation and linear speeds, and friction between the tool shoulder, the probe, and the workpiece, the weld stud length is decided, so it is as close to the root of the weld as possible for full penetration butt welds. Tables 2 and 3 show the final step, known as spacing: pulling the FSW away from the welded material. The model calculates welding force for 1000 steps, and one tooth welder is estimated from the welding force data. Thus, 1000 divided by 60 represents 16.6 revolutions (SPR=60T), where 60 is the number of steps per revolution. Based on this spindle speed, 750 or $47.1 \mathrm{rad} / \mathrm{s}$, TPR $=60 / 4800=0.08$ sec/rev. The tooth period, $1 / \omega T$, where $(T)$ is the number of teeth. Proceeding in small time steps will simulate the process for $\theta \mathrm{E} \leq \theta \leq \theta \mathrm{S}$.

Table 3 Analyzing the forces acting on the probe and the shoulder at different phases

\begin{tabular}{|c|c|c|c|c|c|c|}
\hline Phase & $\begin{array}{c}\text { Probe } \\
\text { Coordinates }\end{array}$ & $\mathbf{F}_{\mathbf{P}}$ & $\begin{array}{c}\text { Shoulder } \\
\text { Coordinate }\end{array}$ & $\mathbf{F}_{\mathbf{S}}$ & $F_{T}=F_{P}+F_{S}$ & \\
\hline \multirow{2}{*}{ Sticking } & \multirow{2}{*}{$\begin{array}{l}X=0, Y=-R_{P}, \\
Z=0\end{array}$} & $-\pi \tau_{\mathrm{c}} \mathrm{R}_{\mathrm{P}}^{2}$ & \multirow{2}{*}{$\begin{array}{l}X x=0, Y=- \\
\left(R_{S}+R_{P}\right), Z=0\end{array}$} & $-\pi \tau_{c}\left(\mathrm{R}_{\mathrm{S}}+\mathrm{R}_{\mathrm{P}}\right) 2$ & $-\pi \tau_{c}\left(R_{S}+R_{P}\right) 2+R p 2$ & \\
\hline & & 0 & & 0 & & \\
\hline \multirow{2}{*}{ Plunging } & \multirow{2}{*}{$\begin{array}{l}X=0, Y=R_{P}=0, \\
Z=-H_{P}\end{array}$} & \multirow[b]{2}{*}{0} & \multirow{2}{*}{$\begin{array}{l}X=0, Y=R s \\
Z=-0.1 \mathrm{Hs}\end{array}$} & $\pi \tau_{\mathrm{c}} \mathrm{R}_{\mathrm{S}}^{2}$ & $\pi \tau_{c} R_{s}^{2}$ & \\
\hline & & & & $5.6228 \mathrm{e}+04$ & $5.6228 \mathrm{e}+04$ & \\
\hline \multirow{2}{*}{$\begin{array}{l}\text { Half } \\
\text { Sliding }\end{array}$} & \multirow{2}{*}{$\begin{array}{l}X=0, Y=R_{P}, \\
Z=-H_{P}\end{array}$} & $\pi \tau_{\mathrm{c}} \mathrm{RP}_{\mathrm{p}}^{2}$ & \multirow{2}{*}{$\begin{array}{l}X=0, Y=2 R_{S-} \\
R_{P}, Z=-0.1 H_{s}\end{array}$} & $\pi \tau_{\mathrm{c}}\left(2 \mathrm{R}_{\mathrm{S}}-\mathrm{R}_{\mathrm{P}}\right)^{2}$ & $\begin{array}{l}\pi \tau c\left[\left(2 \mathrm{R}_{\mathrm{S}^{-}}\right.\right. \\
\left.\left.\mathrm{R}_{\mathrm{P}}\right) 2+\mathrm{R}_{\mathrm{P}}^{2}\right]\end{array}$ & \\
\hline & & $1.4057 \mathrm{e}+04$ & & $1.2651 \mathrm{e}+05$ & $1.4057 \mathrm{e}+05$ & \\
\hline \multirow{2}{*}{$\begin{array}{l}\text { Full } \\
\text { Sliding }\end{array}$} & \multirow{2}{*}{$\begin{array}{l}X=0, Y=2 R_{P} \\
Z=-H p\end{array}$} & $2 \omega \mathrm{FR}_{\mathrm{P}} \mathrm{H}_{\mathrm{P}}$ & \multirow{2}{*}{$\begin{array}{l}X=0, Y=2 R_{S}, \\
Z=-0.1 \mathrm{Hs}\end{array}$} & $2 \omega \mathrm{FR}_{S} 0.1 \mathrm{H}_{\mathrm{S}}$ & $2 \omega \mathrm{F}\left(\mathrm{R}_{\mathrm{P}} \mathrm{H}_{\mathrm{P}}+\mathrm{R}_{\mathrm{S}} \mathrm{H}_{\mathrm{S}}\right)$ & \\
\hline & & $5.6228 \mathrm{e}+04$ & & $2.2491 \mathrm{e}+05$ & $2.8114 \mathrm{e}+05$ & \\
\hline \multirow[t]{2}{*}{$\begin{array}{l}\text { Full } \\
\text { Welding }\end{array}$} & \multirow[t]{2}{*}{$\begin{array}{l}X=0, Y=W_{L}, \\
Z=-H_{P}\end{array}$} & $\omega \mathrm{F}\left(\mathrm{W}_{\mathrm{L}}-\mathrm{R}_{\mathrm{P}}\right) \mathrm{H}_{\mathrm{P}}$ & \multirow[t]{2}{*}{$\begin{array}{l}X=0, Y=W L- \\
R s, Z=-0.1 \mathrm{Hs}\end{array}$} & $\begin{array}{l}\omega \mathrm{F}\left(\mathrm{W}_{\mathrm{L}^{-}}\right. \\
\left.\mathrm{R}_{\mathrm{S}}\right) 0.1 \mathrm{H}_{\mathrm{S}}\end{array}$ & $\begin{array}{l}\omega \mathrm{F}\left[\left(\mathrm{W}_{\mathrm{L}^{-}}\right.\right. \\
\mathrm{Rs}) 0.1 \mathrm{H}_{\mathrm{S}}+\left(\mathrm{W}_{\mathrm{L}^{-}}\right. \\
\left.\left.\mathrm{R}_{\mathrm{P}}\right) \mathrm{H}\right]\end{array}$ & \\
\hline & & $1.1021 \mathrm{e}+07$ & & $9.5025 \mathrm{e}+06$ & $2.0523 \mathrm{e}+07$ & \\
\hline \multirow[t]{2}{*}{ Spacing } & \multirow[t]{2}{*}{$\begin{array}{l}X=0, Y=W L \\
Z=H p\end{array}$} & $\omega \mathrm{F}\left(\mathrm{W}_{\mathrm{L}}-\mathrm{R}_{\mathrm{P}}\right) \mathrm{H}_{\mathrm{P}}$ & \multirow[t]{2}{*}{$\begin{array}{l}X=0, Y=W_{L^{-}} \\
R_{S}, Z=0.1 H^{\prime}\end{array}$} & $\begin{array}{l}\omega \mathrm{F}\left(\mathrm{W}_{\mathrm{L}^{-}}\right. \\
\left.\mathrm{R}_{\mathrm{S}}\right) 0.1 \mathrm{H}_{\mathrm{S}}\end{array}$ & $\begin{array}{l}\omega \mathrm{F}\left[\left(\mathrm{W}_{\mathrm{L}^{-}}\right.\right. \\
\left.\mathrm{R}_{\mathrm{S}}\right) 0.1 \mathrm{H}_{\mathrm{S}}+\left(\mathrm{W}_{\mathrm{L}^{-}}\right. \\
\left.\left.\mathrm{R}_{\mathrm{P}}\right) \mathrm{H}_{\mathrm{P}}\right]\end{array}$ & \\
\hline & & 0 & & 0 & 0 & \\
\hline Total & & & & & $2.0804 \mathrm{e}+07$ & \\
\hline
\end{tabular}

As a result of the computer program, the welder will rotate in steps of 60 per revolution (spr). The angle of engagement $\left(\theta_{\mathrm{E}}-\theta_{\mathrm{S}}\right)$, for full immersion $\mathrm{R}_{\mathrm{D}} / \mathrm{R}=1$, angle of engagement is 180o. In welding, tool rotation angle between consecutive steps is expressed in degrees (dfi), where dfi=360/SPR. If the welding tool is rigid with a dynamic displacement due to the variation of welding force, the total number of steps required to complete the welding engagement (M) will be $180 / \mathrm{dfi}=30$ steps. Consider a slotting weld tool with a $360^{\circ}$ welding 
surface. The mathematical model involving the workpiece's effect leads to a time-varying system, which can be easily investigated through time-domain modeling.

\section{ANALYTICAL MODELLING PROCESS}

Figure 2 illustrates the welding model configuration, consisting of two aluminum plates joined by a $150 \mathrm{~mm}$ long welding path. Initially, the force experienced during the plunge gradually increases after the tool is plunged into the welded panel [26]. Initially, plunging force increases smoothly after the tool penetrates the matrix. After that, defects populate in FSW in a number of ways, which are shown in a FSW process flow diagram (measurable effects during or after welding). FSW is regarded as a symmetrical process with an advancing and retreating side because of the material's dynamic nature throughout the welding process [27]. In this stage, the heated plastic material was moved from the forward to the retracting side of the weld pinhole to fill the hole made by the tool. The majority of it is mixed and consolidated below the tool shoulder as the tool flies along the seam line.

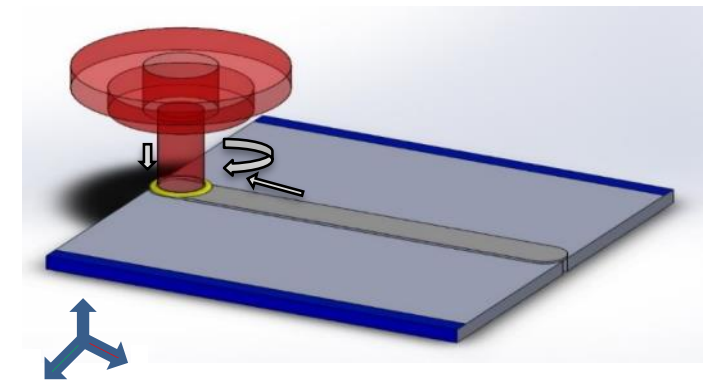

1. Axial force, 2. Rotating speed direction, 3. Tool welding direction, welding speed, 4. Welding force, 5. Friction st welded region, 6. Advancing side, 7. Retreating side of the welding

Figure 2 Orientation diagram and setup of FSW

\section{RESULTS AND DISCUSSION}

As in this study and other similar studies that can be applied to reality in workshops or industrial processes, the welding forces were determined through the phases of FSW, such as feeding force $\left(F_{X}\right)$, the normal force $\left(F_{Y}\right)$, and axial force $\left(F_{Z}\right)$. Heat energies of the tool shoulder and probe were obtained using the equations previously discussed in Tables 3 and 4, as the alloy 2024-T351 is assumed to be welded at the defined rotational and linear speeds. Axial forces perpendicular to the welding piece, $\mathrm{F}_{\mathrm{Z}}$, seem to be more significant than horizontal forces on the piece's surface $F_{X}$ and Fy. Since the surface and parallel forces on the piece's surface and the friction on the machine table do not affect the value of the resultant forces, the total forces are equivalent in content and value to the axial forces. It is also worth mentioning that the axial force in Figure 4 increases as the number of samples decreased to 100.
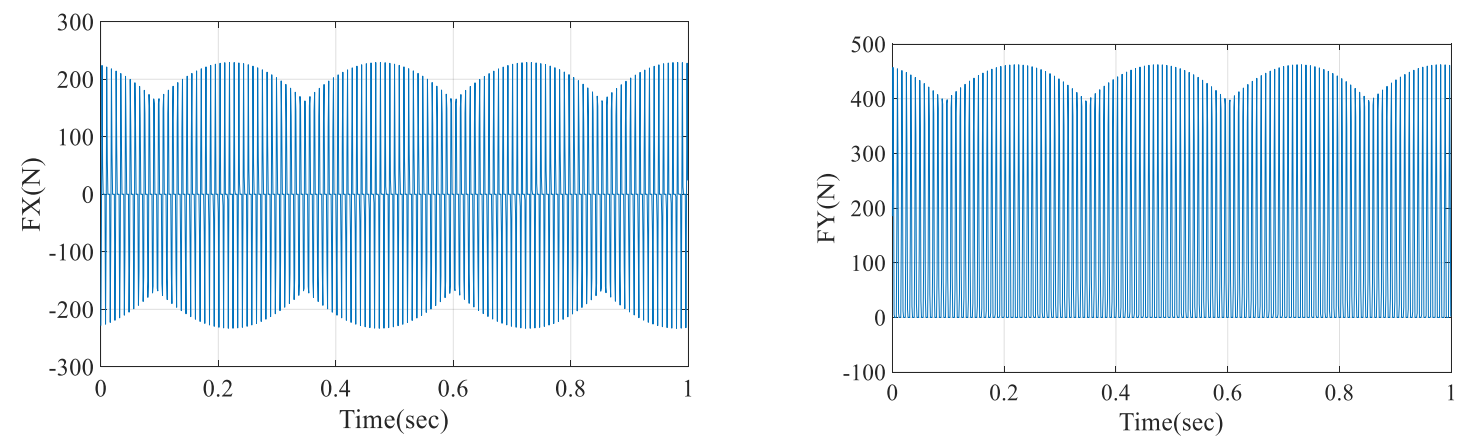


\section{Yaser Hadi}

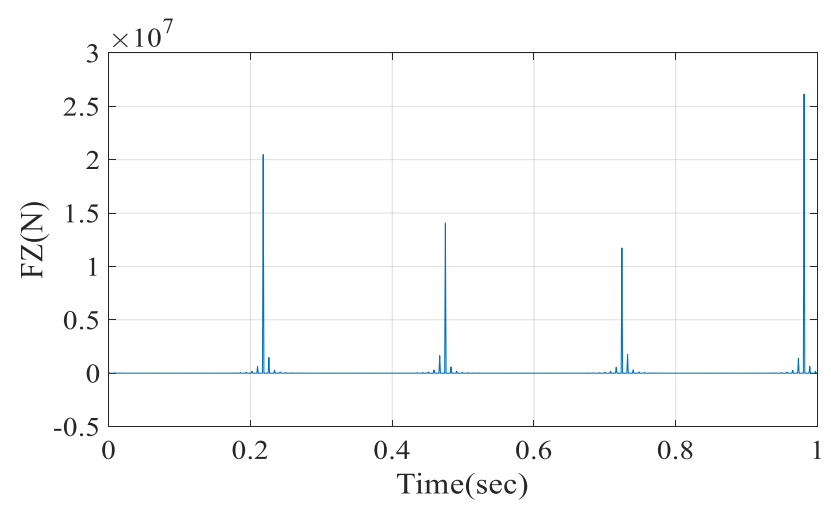

Figure 3. Axial force $\left(\mathrm{F}_{\mathrm{Z}}\right)$, normal force $\left(\mathrm{F}_{\mathrm{Y}}\right)$, and fed force $\left(\mathrm{F}_{\mathrm{X}}\right)$ compared to time units of one second, $750 \mathrm{rpm}$, and 1,000 samples (NS).
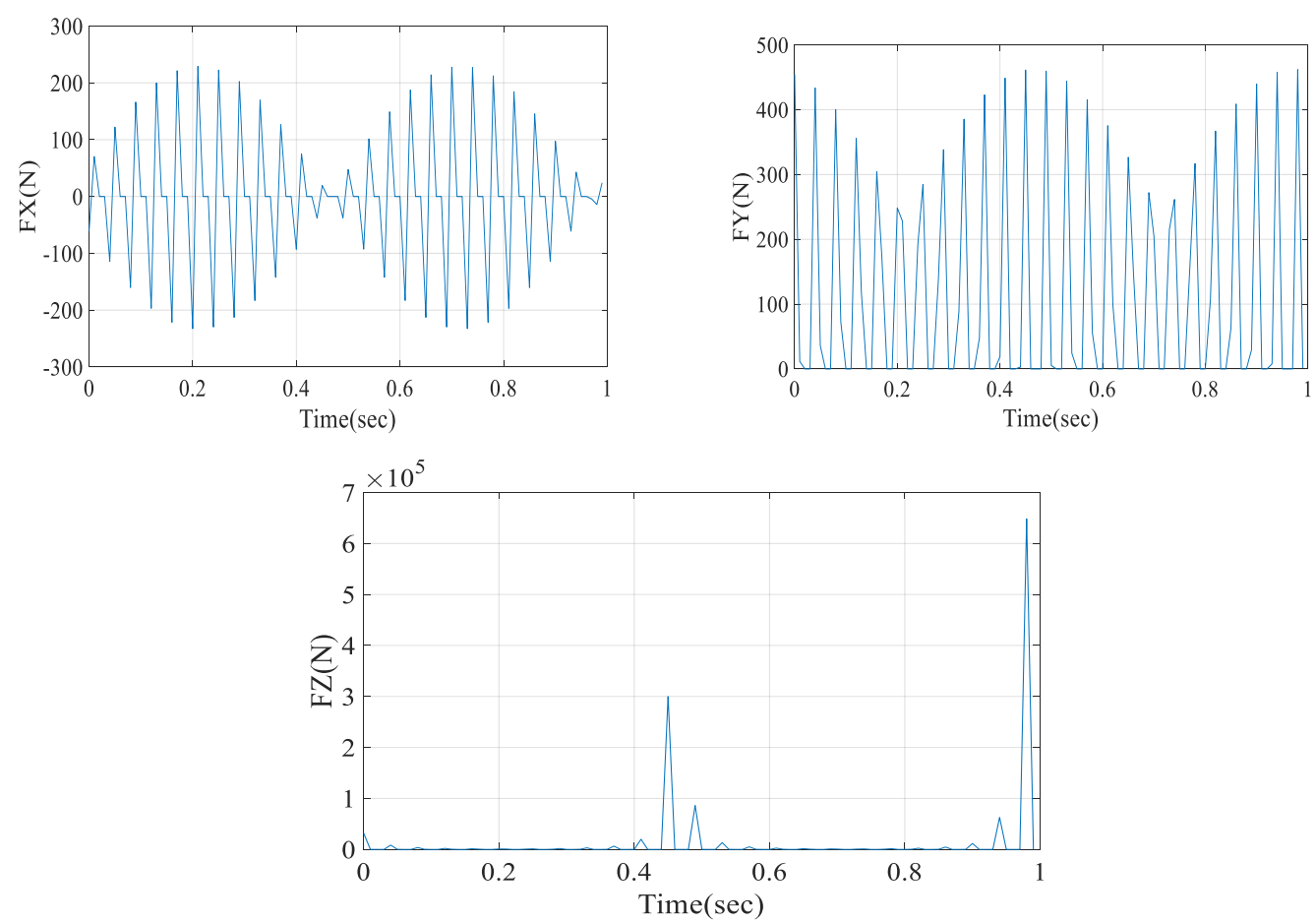

Figure 4. The feed force $\left(\mathrm{F}_{\mathrm{X}}\right)$, the normal force $\left(\mathrm{F}_{\mathrm{Y}}\right)$, and the axial force $\left(\mathrm{F}_{\mathrm{Z}}\right)$, as well as an analogy to time in one second, $750 \mathrm{rpm}$, and 100 samples $\left(\mathrm{N}_{\mathrm{S}}\right)$.

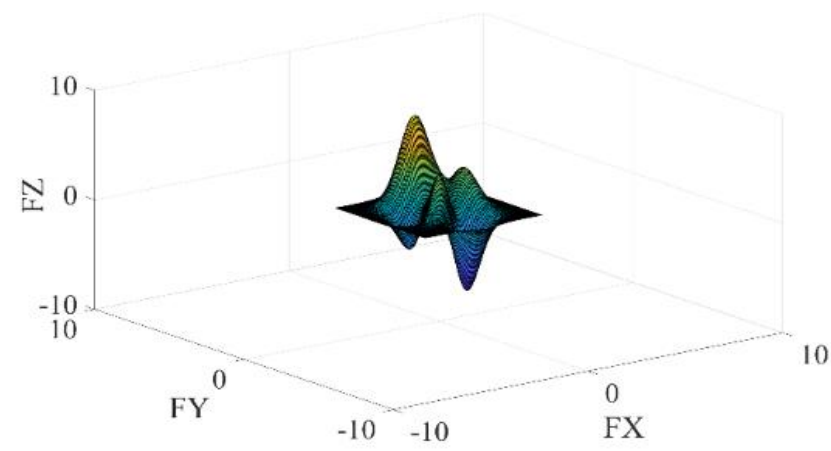

Figure 5. A visualization of the three forces, $\mathrm{F}_{\mathrm{X}}, \mathrm{F}_{\mathrm{Y}}$, and $\mathrm{F}_{\mathrm{Z}}$, while unifying the values of the axes 


\section{CONCLUSION}

The simulations prepared from within a software package using Matlab were intended primarily to study and analyze welding forces and heat generated through various phases activated at certain points for welding piece 2024-T351, based on the parameters outlined in Table 1. The resulting energies from the various equations indicated by $F_{X}, F_{Y}$, and $F_{Z}$ to the weld force model output when friction welding was studied by a theoretical model based on Equations 5, 6 , and 7. It also showed that the vertical force $F_{Z}$ on the welded piece was a force that exists and was as accurate and powerful as the horizontal forces on the joint surface $F_{X}$ and $F_{Y}$. As shown in Fig. 2, the welding tool applied to two welding pieces and made from the same material maintains its stability during the welding process and after one vertical sinking cycle. Models of thermal energy and forces can be applied to the friction welding of any other raw material, incorporating the properties of the changing material into the model. A higher linear speed of welding can lead to higher welding forces and an increase in heat produced, lowering the tensile strength and efficiency of the joint while improving the ductility of the joint. It is worth noting that the value of the axial force $\mathrm{F}_{z}$ obtained by equation 14 is approximately equal to the maximum value in Fig. 3, 2.6133 e+07N. It was not described in the literature review and was first reported in this study.

\section{NOMENCLATURE}

\begin{tabular}{|c|c|}
\hline$F_{X}, F_{Y}, F_{Z}$ & $\begin{array}{l}\text { Forces acting on the feed, normal, and axial axes, } \\
\text { respectively, } \mathrm{N}\end{array}$ \\
\hline$f_{S}, f_{P}$ & Heat generation ratios on the shoulder and probe, $\mathrm{m}$ \\
\hline $\mathrm{H}_{\mathrm{P}}, \mathrm{H}_{\mathrm{S}}, \mathrm{H}_{\mathrm{T}}$ & Probe, shoulder, and total depths of welding, $\mathrm{m}$ \\
\hline $\mathrm{Q}_{\mathrm{S}}, \mathrm{Q}_{\mathrm{P}}, \mathrm{Q}_{\mathrm{T}}$ & $\begin{array}{l}\text { The generation of heat from the shoulder, the probe, and the } \\
\text { Total, J/s. }\end{array}$ \\
\hline RS, RP & Radii of tool shoulders and probes, $\mathrm{m}$ \\
\hline $\mathrm{W}_{\mathrm{L}}, \mathrm{W}_{\mathrm{W}}, \mathrm{W}_{\mathrm{T}}$ & The length, width, and thickness of the workpiece, $\mathrm{m}$ \\
\hline $\mathrm{Z}$ & Rotation axis dimension, $\mathrm{m}$ \\
\hline$\tau \mathrm{c}$ & The shear stress at the contact surface, $\mathrm{Pa}$ \\
\hline$\mu$ & The friction coefficient \\
\hline$\omega$ & The angular rotation speed of the weld tool, $\mathrm{rad} / \mathrm{s}$ \\
\hline$\delta$ & The state variable of contacts \\
\hline $\mathrm{R}$ & Position along the tool radius, $\mathrm{m}$ \\
\hline$\theta$ & Angle, degree \\
\hline$\sigma_{\text {yield }}$ & The yield tensile stress, $\mathrm{Pa}$ \\
\hline
\end{tabular}

\section{FUTURE WORK}

The welding parameters listed in Table 1 can be utilized to achieve the FSW modeling based on the welder's instantaneous tangential $\left(\mathrm{F}_{\mathrm{T}}\right)$ and radial $\left(\mathrm{F}_{\mathrm{R}}\right)$ welding forces.

\section{REFERENCES}

[1] T.A Barnes I. R Pashby, "Joining techniques for aluminum spaceframes used in automobiles: Part I solid and liquid phase welding”, Journal of Materials Processing Technology, 99, 1-3, 2000, pp. 62-71.

[2] Bahman Meyghani, Mokhtar B. Awang, Seyed Sattar Emamian, Mohd Khalid B. Mohd Nor, and Srinivasa Rao Pedapati, "A Comparison of Different Finite Element Methods in the Thermal Analysis of Friction Stir Welding (FSW)", MDPI, Metals, 7(10), 2017, 450; https://doi.org/10.3390/met7100450.

[3] R. K. Uyyuru, Satish V. Kailas, "Numerical analysis of friction stir welding process", Springer, Journal of Materials Engineering and Performance, 15, pp. 2006, 505-518. 
[4] H.I. Dawood, Kahtan S. Mohammed, Azmi Rahmat, M.B. Uday.” Effect of small tool pin profiles on microstructures and mechanical properties of 6061 aluminum alloy by friction stir welding", Transactions of Nonferrous Metals Society of China, 25, 9, 2015, pp. 2856-2865.

[5] Galvão, R.M. Leal, D.M. Rodrigues, A. Loureiroa, "Influence of tool shoulder geometry on properties of friction stir welds in thin copper sheets", Journal of Materials Processing Technology, 213, 2, 2013, pp. 129-135.

[6] Danial Ghahremani Moghadam, Khalil Farangdoost,"Influence of welding parameters on fracture toughness and fatigue crack growth rate in friction stir welded nugget of 2024-T351 aluminum alloy joints", Transactions of Nonferrous Metals Society of China, 26, 10, 2016, pp. 2567-2585.

[7] C.M. Chen, R. Kovacevic, "Finite element modeling of friction stir welding-thermal and thermomechanical analysis", International Journal of Machine Tools and Manufacture, 43, 13, 2003, pp. 1319-1326.

[8] Vinayak Malik, N.K. Sanjeev., "Review on modeling of friction stir welding using finite element approach and significance of formulations in simulation", International Journal of Manufacturing Research, 15, 2, 2020, DOI: 10.1504/IJMR.2020.106851.

[9] Dana Ashkenazi, "How aluminum changed the world: A metallurgical revolution through technological and cultural perspectives", Technological Forecasting and Social Change, 143, 2019, pp. 101-113.

[10] Evangelia Georgantzia, Michaela Gkantou, George S. Kamaris, "Aluminum alloys as structural material: A review of research”, Engineering Structures, 2021, 227, 111372.

[11] Mahdi Masoumi Khalilabad, Yasser Zedan, Damien Texier, Mohammad Jahazi, PhilippeBocher, "Effect of tool geometry and welding speed on mechanical properties of dissimilar AA2198-AA2024 FSWed joint", Journal of Manufacturing Processes, 34, A, 2018, pp. 86-95.

[12] Weifeng Xu, Yuxuan Luo, Wei Zhang, Mingwang Fu, "Comparative study on local and global mechanical properties of bobbin tool and conventional friction stir welded 7085-T7452 aluminum thick plate", Journal of Materials Science \& Technology, 34, 1, 2018, pp. 173-184.

[13] X.C. Liu, Y.F. Sun, T, "Nagira, K.Ushioda, H. Fujii. Evaluation of dynamic development of grain structure during friction stir welding of pure copper using a quasi-in situ method", Journal of Materials Science \& Technology, 35, 7, 2019, pp. 1412-1421.

[14] Abootorab Baqerzadeh Chehreh, Michael Grätzel, Jean Pierre Bergmann, and Frank Walther, "Effect of Corrosion and Surface Finishing on Fatigue Behavior of Friction Stir Welded EN AW-5754 Aluminum Alloy Using Various Tool Configurations”, MDPI, Materials, 13 (14), 3121; 2020, https://doi.org/10.3390/ma13143121.

[15] Oyindamola Kayode, and Esther Titilayo Akinlabi. An overview on joining of aluminum and magnesium alloys using friction stir welding (FSW) for automotive lightweight applications. Materials Research Express, Volume 6, Number 11, 2019.

[16] A.F. Hasan, "CFD modeling of friction stir welding (FSW) process of AZ31 magnesium alloy using the volume of fluid method" Journal of Materials Research and Technology, 8, 2, 2019, pp. $1819-1827$.

[17] H Schmidt, J Hattel, and J Wert, "An analytical model for the heat generation in friction stir welding", Modeling and Simulation in Materials Science and Engineering, 12, 2004, pp. 143157.

[18] Yuh J. Chao, Mem. ASME, X. Qi, W. Tang, "Heat Transfer in Friction Stir Welding Experimental and Numerical Studies", Journal of Manufacturing Science and Engineering, 125, (1), 2003, pp. 138-145. 
[19] Miroslav Mijajlović, and Dragan Milčić, “Analytical Model for Estimating the Amount of Heat Generated During Friction Stir Welding: Application on Plates Made of Aluminium Alloy 2024 T351”, Welding Processes, 2012, http://dx.doi.org/10.5772/53563.

[20] Peyman Shahi, and Mohsen Barmouz, "Force and torque in friction stir welding", Advances in Friction Stir Welding and Processing”, 2014, pp. 459-498, DOI: 10.1533/9780857094551.459.

[21] Karen J. Quintana, Jose Luis L. Silveira, "Analysis for the forces in FSW for aluminum alloy considering tool geometry and process velocities", Journal of the Brazilian Society of Mechanical Sciences and Engineering, 40, 229, 2018, https://doi.org/10.1007/s40430-0181162-0.

[22] D. Trimble, J. Monaghan, G. E. O'Donnell, "Force generation during friction stir welding of AA2024-T3", CIRP Annals, 61, 1, 2012, pp. 9-12.

[23] N. Dialami, M. Chiumenti, M. Cervera, A, "Segatori, W.Osikowicz. Enhanced friction model for Friction Stir Welding (FSW) analysis: Simulation and experimental validation", International Journal of Mechanical Sciences, 133, 2017, pp. 555-567.

[24] H. Sua, C. S. Wu, A. Pittner, M. Rethmeier, "Simultaneous measurement of tool torque, traverse, force, and axial force in friction stir welding", Journal of Manufacturing Processes, 15, 4, 2013, pp.495-500.

[25] Gerbson de Queiroz Caetano, Cleiton Carvalho Silva, Marcelo Ferreira Motta, Hélio Cordeiro Miranda, Jesualdo Pereira Farias, Luciano Andrei Bergmann, JorgeF. dos Santos, "Influence of rotation speed and axial force on the friction stir welding of AISI 410S ferritic stainless steel", Journal of Materials Processing Technology, 262, 2018, pp. 430-436.

[26] H Schmidt, J Hattel1, and J Wert2, "An analytical model for the heat generation in friction stir welding", Modeling and Simulation in Materials Science and Engineering, 12, 1, 2003

[27] H. N. B. Schmidt, T. L. Dickerson, J. H. Hattel, "Material flow in butt friction stir welds in AA2024-T3", Acta Materialia, 54, 4, 2006, pp.1199-1209. 